\title{
CINCO TEMAS ACTUALES Y POLÉMICOS EN EL DERECHO COLECTIVO DEL TRABAJO*
}

\author{
Hugo Barretto Ghione*** \\ Como vencer o oceano \\ Se é livre a navegaçâo \\ Mas proibido fazer barcos? \\ C. Drummond de Andrade
}

RESUMO: O artigo aborda os polêmicos conceitos de trabalho subordinado e empresa e o seu impacto no direito coletivo, a autonomia ou heteronomia na negociação coletiva, a institucionalização do sujeito sindical e a autal judicialização do conflito coletivo, o problema da tensão entre a diretiva constitucional de promoção sindical e as liberdades individuais e a opacidade da interpretação das normas jurídicas como espaço de contradição apontam.

\section{INTRODUCCIÓN}

El derecho colectivo del trabajo siempre ha estado sujeto a debate, lo que no hace mas que traducir su carácter fuertemente político, al inscribirse como regulador fundamental de las relaciones entre capital y trabajo y

* Ponencia presentada en el XIX Encontro dos Juízes do Trabalho do Rio Grande do Sul.

** Master en Derecho del trabajo y la seguridad social (Universidad de la República - Uruguay). Profesor adjunto de derecho del trabajo y la seguridad social y de relaciones laborales. Profesor de "teoría general del derecho del trabajo" en el post grado de derecho del trabajo y la seguridad social en la Universidad dela República creador de una institucionalidad ${ }^{1}$ particular de esas relaciones.

El itinerario histórico de esa polémica denota la evolución de las ideas juslaboralistas: primero, el derecho colectivo debió debatirse

${ }^{1}$ MONEREO PÉREZ, José Luis. Introducción al Nuevo Derecho del Trabajo. Una reflexión crítica sobre el derecho flexible del trabajo. Tirant lo Blanch, Valencia, 1996, p. 16. W. Daübler indica que "el derecho del trabajo cumple con dos funciones que se pueden comparar con dos caras de una moneda: se ocupa de que las condiciones de intercambio no se puedan deteriorar arbitrariamente a costa de los trabajadores y al propio tiempo crear las condiciones para que continúen subsistiendo las circunstancias económicas y políticas existentes". En Derecho del Trabajo. MTSS. Madrid. 1994, p. 90 
para justificarse e imponerse como sector del ordenamiento jurídico en un derecho básicamente adscrito a los postulados del Estado liberal clásico, lo cual supuso algún quiebre de su ortodoxia, que para algunos críticos no significó otra cosa que la simple adaptación del capitalismo a las nuevas condiciones de poder de la clase subalterna.

En su etapa de crecimiento, a mediados del siglo pasado, el derecho colectivo comportó la madurez de sus instituciones principales, la negociación colectiva y la huelga, que dibujaron un escenario para la puja por la distribución y la participación de los trabajadores en el producido de la empresa, todo ello enancado en el reconocimiento constitucional e internacional de esos derechos a través de los instrumentos arquetípicos.

Por último, el derecho colectivo del trabajo será objeto del embate neoliberal, que procuró tanto reforzar la reglamentación limitativa del conflicto y la organización sindical, como instrumentalizar la negociación colectiva como vehículo para posibilitar la desregulación de la relación individual de trabajo.

Seguramente se imponga hoy una nueva mirada a estos fenómenos, que permita descubrir lo que quedó en pié y siente las bases de su actualización, que de ningún modo puede suponer una restauración del pasado. Por ello estudiar los aspectos polémicos del derecho colectivo es revisitar esta zona del ordenamiento para identificar sus principales y actuales perfiles, tal como se propone de inmediato.
II. INNOVACIÓN Y TRADICIÓN EN EL DERECHO COLECTIVO DEL TRABAJO: GÉNESIS Y PROCEDENCIAS DE SUS PRINCIPALES PROBLEMAS

\section{a) Precisiones}

Al interrogarnos sobre los aspectos polémicos del derecho colectivo, no deben soslayarse un par de consideraciones.

En primer término, ha de reconocerse la radical historicidad del derecho colectivo. Se impone un abordaje diacrónico que incorpore los elementos del contexto social, económico y cultural del cual es parte. Los enfoques en derecho colectivo serán aproximativos y provisorios, y el giro dado recientemente a las relaciones de trabajo en Uruguay parece demostrar la falta de poder explicativo que tienen los puntos de vista que se pretenden como definitivos y universales. Ello señala las dificultades de desplegar una teoría general, limitación que Barbagelata ${ }^{2}$ ha reducido al "alcance medio" de los intentos dogmáticos. No obstante, esta constatación no equivale a decir que sea infructuoso o imposible todo esfuerzo sistematizador ni que no aparezcan ciertas estructuras jurídicas en el derecho del trabajo sobre las cuales no valga la pena ensayar una interpretación teórica de relevancia. Dice al respecto Perone ${ }^{3}$ que defiende "que el sistema juslaboralista deba

${ }^{2}$ BARBAGELATA, Héctor-Hugo. El Particularismo del Derecho del Trabajo. FCU. Mont. 1995

3 PERONE, Giancarlo. "Crise nos elementos estructurais do ordenamento justrabalista italiano: tendências evolutivas e aspectos criticos". En el vol. Avanços e posibilidades do direito do trábalo. Luiz A. de Vargas y Ricardo Carvalho Fraga (Coord.) LTr, 2005 p. 188 
ser considerado en su incesante dinamicidad, sin perder de vista los pocos y esenciales factores constitutivos".

En definitiva, pese a su mutabilidad y plasticidad (recuérdese que De la Cueva ${ }^{4}$ hablaba del derecho del trabajo como un derecho inconcluso), nuestra disciplina presenta una estructura, principios y particularismos que delinean ciertas permanencias que lo identifican como material y conceptualmente diverso del derecho común.

En segundo lugar, esa continua normatividad generada por la negociación colectiva y la huelga determina que el estudio del derecho colectivo rinda mejor cuenta de la realidad cuando se lo circunscribe a una comarca determinada.

Modelos de relaciones colectivas de trabajo tan históricamente disímiles como el brasileño y el uruguayo demandan por tanto aproximaciones muy generales y cautas para, a lo sumo, establecer correspondencias, líneas de tendencia y evoluciones en la legislación y las prácticas laborales. Quizá sea en el ámbito de las prácticas, justamente, donde deban hallarse las mayores y más significativas coincidencias.

\section{b) Un ensayo de clasificación}

Para un ensayo de clasificación de los aspectos polémicos, podrían tomarse como variables la novedad temática, la procedencia y las prácticas que producen los actores.

En relación a la variable "novedad" que puedan despertar los aspectos polémicos del derecho colectivo, es posible diferenciar

${ }^{4}$ DE LA CUEVA, Mario. El Nuevo Derecho Mexicano del Trabajo. Porrúa. 1990, p. 98 los nuevos de los viejos problemas, y aún dentro de éstos, verificar que no en pocos casos muestran perfiles actuales muy nítidos y diferenciados de los habituales.

Así, la tradicional y dicotómica relación autonomía/heteronomía, sin dejar de ser una cuestión central desde el origen mismo del derecho del trabajo, puede adquirir en la coyuntura diversas formulaciones, propias de la configuración reciente de las relaciones laborales y del poder que ostentan los actores en la etapa histórica contemporánea, que amplían o restringen el margen de autonomía de acuerdo al juego de intereses, estrategias y posibilidades.

El relevamiento del derecholatinoamericano reciente da cuenta precisamente de esa la oscilación de los sistemas en torno a esa polaridad, sobre cuyos extremos podrá "inclinarse la balanza". En el caso uruguayo, debe decirse desde ya que muchos observadores se han preguntado si no se está en tránsito hacia un modelo de mayor intervencionismo estatal 5 .

De todos modos, para advertir mayor grado de novedad en el derecho colectivo de nuestros días habrá que hilar mas finamente, y preguntarse, por ejemplo, si la falta de una disciplina que regule el conflicto colectivo no es sustituida por la actividad jurisdiccional, sospecha que adquiere

\footnotetext{
${ }^{5}$ Básicamente, los cambios de mayor profundidad a partir de la asunción del nuevo gobierno en marzo de 2005 fueron la convocatoria a negociar salarios mínimos por sector de actividad, abandonando así la prescindencia estatal sobre estos asuntos; la sanción de la ley núm. 17.940 de libertad sindical, que impone la reinstalación en su lugar de trabajo del trabajador despedido o discriminado y la extensión de la negociación colectiva al sector público de la Administración Central.
} 
contornos reales si se repara en ciertos pronunciamientos judiciales recientes sobre ocupaciones de los lugares de trabajo de los que se dará cuenta mas adelante.

Otro problema de largo linaje en el derecho colectivo pero de renovado interés, es el referido a la libertad sindical en su dimensión individual y su eventual colisión con los derechos colectivos.

Si en cambio atendemos a la variable "procedencia", hallaremos problemas que pueden considerarse propios del derecho colectivo del trabajo - endógenos - y problemas que por el contrario son en principio ajenos al derecho colectivo (con la relatividad de estas distinciones) pero que no obstante lo impactan -exógenos -. Se trata de algunos debates que se sitúan en la órbita mas general del mundo del trabajo y que terminan inevitablemente modulando el derecho colectivo.

En concreto, nos estamos refiriendo a procesos como la externalización (o desmembramiento) empresarial y a la evolución de las ideas en torno al concepto de "trabajo subordinado". Ambos asuntos comparten afinidades y trayectorias comunes, y en su conjunto han determinado, por ejemplo, la llamada "huída" del derecho del trabajo o "desenfoque" del ámbito de las relaciones de trabajo, para emplear un término adoptado por los documentos preparatorios de la OIT sobre la reciente Recomendación sobre la Relación de Trabajo (2006) ${ }^{6}$.

Queda por último reconocer que en el ámbito de su autonomía, los actores del mundo del trabajo - las organizaciones de

${ }^{6}$ El Ámbito de la Relación de Trabajo. Informe V. Oficina Internacional del Trabajo, $91^{\circ}$ reunión, 2003 trabajadores y de empleadores - desarrollan sus estrategias y de ese juego surge la materia prima indispensable para la investigación, la reflexión y divulgación de los estudios del derecho colectivo. Nos situamos así en el tercer eje de análisis, el de las prácticas de los operadores.

En este punto, cabe anotar que la doctrina no siempre reflexiona sobre sí misma, pareciendo rehuir de la "metateoría" y de los abordajes "introspectivos". En esta dirección, a menudo se observa que el debate doctrinario e interpretativo queda reducido a una labor casi doméstica, pretendidamente neutra o cientificista, evitando reconocer que se trata, por el contrario, de uno de los espacios de mayor diferenciación y polémica en el derecho del trabajo. No se advierte o reconoce que la divulgación de esos "productos" de la elaboración teórica resultan en definitiva un componente sustantivo de las transformaciones de las prácticas del derecho colectivo, que a su vez, conforman su objeto de estudio, como en un mecanismo retroalimentado ${ }^{7}$.

Däubler, trasparentando lo que ocurre en la trastienda, señalaba - para el caso de Alemania - que la discusión científica en

${ }^{7}$ En algunos casos la polémica en torno a la configuración del derecho se formula ríspidamente: “el único instrumento para quitarle al derecho el repugnante esmalte potestativo y autoritario tradicional era y es concebir su producción como un procedimiento que no termina con la aprobación de la norma sino que tiene un momento subsiguiente, el interpretativo, como momento propio de la formación de la realidad compleja de la norma, en suma, la interpretación como momento esencial de la posibilidad de la misma norma, condición necesaria para la concreción de su positividad". Grossi, Paolo. Mitología Jurídica de la Modernidad. Trotta. Madrid, 2003, p. 59 
derecho del trabajo no constituye casi nunca un tema que se vea libre del poder ${ }^{8}$.

Se genera así una dinámica triádica de a) identificación de los problemas o los materiales del derecho colectivo (normas, conflictos, pretensiones, manifestaciones); b) procesamiento de esos materiales en el ámbito interpretativo - doctrinal; y c) resultados y productos (bajo la forma de opiniones, dictámenes, sentencias, estudios) que una vez divulgados, retornan a la realidad social, incidiendo y coadyuvando para su transformación. La retroalimentación opera de forma tal que, la nueva interpretación de la norma (que no es otra cosa que una nueva norma), la solución de un conflicto, o el nuevo enfoque jurídico, pasan a ser parte del problema nuevamente.

El debate doctrinario o jurisprudencial es así concebido como una lucha simbólica ${ }^{9}$, y la magnitud de su influencia no debe ser desconocida, ocultada o minimizada. El carácter marcadamente social y "político" del derecho colectivo del trabajo hace difícil la opacidad de la controversia teórica, o la maniobra casi distractiva que consiste en sostener que se trata de un ámbito neutro, al margen de las controversias nucleares que sustentan materialmente la disciplina laboral. Siendo un campo de contradicción doctrinal, conviene identificar algunos de los ejes actuales del desacuerdo y las alternativas existentes, a fin de contribuir a su síntesis y superación.

\footnotetext{
${ }^{8}$ DÄUBLER, Wolfgang, cit. p. 79

${ }^{9}$ BOURDIEU, Pierre. Poder, Derecho y Clases Sociales. Descelée de Brouwer. Bilbao. 2000
}

\section{III) ASPECTOS POLÉMICOS (Y DILEMÁTICOS) DEL DERECHO COLECTIVO}

Es posible diferenciar cinco núcleos temáticos fuertemente polémicos, cuando no dilemáticos, que se traducen casi siempre en pares binarios que confrontan valores o perspectivas disímiles y hasta antitéticas.

\section{A. El itinerario de los conceptos de trabajo subordinado y empresa y su impacto en el derecho colectivo}

El debate en torno al concepto de trabajo se sitúa extramuros del derecho colectivo, pero dada la natural indisociabilidad entre las dimensiones individual y colectiva del derecho del trabajo o, a lo sumo, de la delgada línea que los separa, es inevitable que el derecho colectivo recepte el problema, y a su manera lo module.

Para aproximarse a la cuestión, y en lo que ahora importa, corresponde efectuar un breve recorrido sobre los puntos en disputa, aunque para ello haya que dar un rodeo sobre el tema central.

El término trabajo se encuentra sometido a controversia. Ingresar al debate es abrirse a una multiplicidad de perspectivas y enfoques que confluyen, de los cuales el encare jurídico no es el único ni seguramente el principal: la filosofía y la teoría social, la economía y la cultura tienen explicaciones sobre el origen y el alcance del fenómeno. El estudio de sus perfiles jurídicos deberá tramontar esa cuesta y registrar algunos de esos aportes en un juego interdisciplinario que no pierda la bitácora del derecho. 
El debate comporta también otros riesgos, como el de sumergirse en una bibliografía prácticamente inabarcable y de raigambre básicamente europea, que puede eventualmente distraer al lector del lugar desde donde se sitúa el análisis. Por ello, sin cometer la inconsistencia de desechar ningún aporte, debería hacerse una lectura "situada" y crítica. En este sentido, el llamado "fin del trabajo", entendido como fenómeno vinculado a la postmodernidad y al pensamiento débil, no es absolutamente identificable con el (¿mismo?) fenómeno visto y sufrido desde la periferia del mundo industrializado, por mas que, en razón de una visión mundial o global, los orígenes puedan ser comunes ${ }^{10}$.

El trabajo tal cual lo conocemos es una invención del capitalismo, dicen con diverso énfasis muchos autores. La característica esencial del trabajo a partir de la economía de mercado es la de ser una actividad en la esfera pública, demandada, definida, reconocida útil por otros, y como tal remunerada por ellos, dice Gorz ${ }^{11}$. Su importancia es tal que es mediante el trabajo asalariado por lo que pertenecemos a la esfera pública y obtenemos una identidad social y personal. Por ello el trabajo necesario para la subsistencia (doméstico, de autoproducción) no pudo jamás convertirse, dice este autor, en un factor de integración social. Es mas bien un principio de exclusión: quienes lo realizaban eran tenidos como inferiores en todas las

${ }^{10}$ RACCIATTI, Octavio Carlos. "Los significados del trabajo en las relaciones laborales”. Rev. Relaciones Laborales. Núm. 10. Mont. 2006, p. 29

${ }^{11}$ GORZ, André. La Metamorfosis del Trabajo. Sistema. P. 26 sociedades premodernas, y constituía una actividad servil que excluía la ciudadanía, según Hanna Arendt.

Ahora bien: pese a esa ubicación ciertamente central en la sociedad industrial, subsistió una muy fuerte diferenciación entre los diversos tipos de trabajo.

Para Galbraith ${ }^{12}$, el trabajo no podía de ningún modo ser homogeneizado, puesto que para algunos siguió siendo una carga que debía de soportarse aún cuando sea mas deseable que no tener nada que hacer, mientras que para otros se trataba de una actividad atractiva y creativa, prestigiosa y económicamente provechosa.

Las referencias del economista canadiense a la índole diversa de los trabajos replanteaba las bipolaridades clásicas ${ }^{13}$, que se entroncan con las visiones primigenias del trabajo humano:

$$
\begin{aligned}
& \text { manual/intelectual } \\
& \text { ejecución/planeación } \\
& \text { rutinario/creativo } \\
& \text { material/simbólico } \\
& \text { objetivo/subjetivo }
\end{aligned}
$$

Completando esta evolución, recientemente Negri y Hart ${ }^{14}$ hablan del trabajo afectivo, entendido como aquel que produce o manipula afectos, como las sensaciones gratas o de bienestar (trabajo de las azafatas, de las casas de comida rápida, estrategias de marketing, etc).

Estos diversos modos de trabajar disparan una serie de problemas tradicionales y nuevos

\footnotetext{
${ }^{12}$ GALBRAITH, John Kennet. La Sociedad Opulenta. Obras Maestras del Pensamiento Contemporáneo. Planeta - Agostini, Barcelona, 1984. p. 279-290

13 BARRETTO GHIONE, Hugo. "John $K$. Galbraith: reflexiones sobre el trabajo”. Rev. Derecho Laboral T. XLIX, núm. 222 p. 419

${ }^{14}$ NEGRI, Antoni y Hart, Michael. Multitud. Guerra y Democracia en la era del Imperio. Debate. Bs.As. 2004
} 
para el derecho del trabajo en general y para el derecho colectivo en particular.

Así, la norma laboral debe dar cuenta tanto de las particularidades de cada trabajo (descripción de las tareas o funciones, nivel retributivo, condiciones de trabajo), como de la pretensión de universalidad de su regulación.

Este desafío está presente en la estrategia misma de los actores sociales, en cuanto puede presentarse como una oportunidad de fragmentar intereses que otrora fueron solidarios y comunes, y hoy pueden ser instrumentados para individualizar la relación de trabajo y cooptar a los trabajadores. Del lado sindical, por el contrario, al momento de negociar el convenio colectivo deberán contemplar y representar esa diversidad de modos de trabajar sin perder la identidad colectiva de la categoría de asalariados.

Otro orden de problemas vinculados con el concepto actual de trabajo y de empresa aparece cuando se observa la organización actual de la producción.

Bauman ${ }^{15}$ cuando fundamenta su concepto de modernidad sólida lo hace a partir del compromiso histórico de capital y trabajo, mediante el cual la supervivencia de los trabajadores dependía de que fueran contratados, y la reproducción y el crecimiento del capital dependían, a su vez, de la contratación de trabajadores. Capital y trabajo estaban unidos, decía Bauman, y la fábrica era su domicilio común: simultáneamente campo de batalla de una guerra de trincheras y hogar natural de sueños y esperanzas.

El papel del Estado era el de velar por el capital para que estuviese en condiciones

${ }^{15}$ BAUMAN, Zygmunt. Modernidad Líquida. Paidos. p. 153 y ss de comprar trabajo y afrontar sus costos; a su vez, la seguridad social permitía la conservación de un ejército de reserva pronto y adiestrado para entrar en acción.

Sin embargo, ese mundo sólido del trabajo ha sido progresivamente sustituido por la incertidumbre y la inestabilidad, y los "miedos, ansiedades y aflicciones deben ser sufridas en soledad. No se suman, no se acumulan hasta convertirse en una causa común ni tienen discurso específico". Por ello la actual versión dispersa, diseminada, fluida del capitalismo se basa en un desprendimiento y debilitamiento de los lazos de capital y trabajo.

En palabras de Bauman: "el capital se soltó de la dependencia que lo ataba al trabajo gracias a una libertad de movimiento impensable en el pasado (...) la reproducción del crecimiento y la riqueza, de las ganancias y de los dividendos y la satisfacción de los accionistas son independientes de la duración de cualquier compromiso local y particular con el trabajo".

En su vertiente mas radical, Medá ${ }^{16}$ dirá que el trabajo es el medio de realización de la vida humana solo por accidente y no por esencia, y que fue el siglo XVIII el que lo inventó y catapultó como categoría homogénea, o sea, como principal factor de producción, intercambio económico, núcleo o fundamento de la vida social.

Una de las expresiones mas acabadas de este debilitamiento del vínculo capital/trabajo lo constituye el proceso de flexibilización laboral producto de la tercerización y

${ }^{16}$ MÉDA, Dominique. "El valor trabajo visto en perspectiva” Revista Internacional del Trabajo. Vol. 115, núm. 6. 1996, p. 689 
descentralización empresarial, que determina la confusión acerca de la figura del sujeto empleador, oculto tras una trama y una cadena difusa de relaciones inter empresariales (subcontratación, empresas de trabajo temporal, diversos tipos de intermediación, etc).

En síntesis, el desmembramiento de la empresa en variadas unidades productivas que trabajan en red respecto de una entidad central cada vez mas difuminada, comporta uno de los problemas "existenciales" del sujeto colectivo sindical. A menudo tanto: a) la determinación del empleador, por las configuraciones variopintas, cuando no fraudulentas; como b) la articulación del interés de los trabajadores de las micro y pequeñas empresas que trabajan en el entorno de la empresa principal, constituirán escollos difíciles de sortear en el terreno de lo jurídico y en las prácticas sindicales. Ejemplos de respuestas de los trabajadores son la afiliación de los asalariados de empresas tercerizadas al sindicato de la empresa principal, o la integración y representación de los intereses de los trabajadores de las subcontratistas en la unidad de negociación principal, etc.

Del lado de los empleadores, la desarticulación del interés colectivo fragmentado en una miríada de micro sujetos, o de trabajadores individualmente considerados, cooptados o mas que nunca hiposuficientes, comporta el otro extremo de la polaridad dilemática que hacíamos referencia supra.

El alcance de los problemas aquí meramente esbozados es de tal magnitud, que constituyen un desafío mayor, pese a que la misma negociación colectiva ha comenzado a dar algunas soluciones en materia de trabajo prestado a través de empresas suministradoras de trabajo temporal, dato auspicioso para el derecho colectivo del trabajo ${ }^{17}$.

\section{B. Autonomía/heteronomía en la negociación colectiva y el conflicto: antes que un cambio, la consolidación de un "modelo aluvional"}

La dicotomía autonomía/heteronomía constituye una de las tradicionales aporías del derecho colectivo, que le acompaña desde su mismo origen. Las relaciones colectivas de trabajo han estado en América Latina fuertemente determinadas por la legislación, que en general ha incidido en un sentido de limitar el desarrollo autónomo de los sindicatos, con motivo en razones políticas, económicas y sociales ${ }^{18}$.

Los cambios recientes en la legislación latinoamericana parecen abrir cauces a un mayor grado de libertad sindical, al menos en lo que hace a la letra de la ley; quedará por verificar su impacto real en las prácticas laborales.

De acuerdo a una sistematización de las innovaciones hecha por Von Potosky ${ }^{19}$,

${ }^{17}$ En concreto, el convenio colectivo suscrito entre la Cámara Uruguaya de Empresas Suministradoras de Personal y FUECI de fecha 29 de julio de 2005 y extendido al ámbito nacional por decreto de 22 de setiembre de 2005 , establece en su cláusula $4^{\circ}$ que "a partir del $1^{\circ}$ de julio de 2005 los trabajadores empleados a través de una empresa suministradora de personal (...), no podrán recibir una remuneración inferior al mínimo salarial obligatorio que marque la categoría en la que desempeñe sus funciones y que corresponda al sector de actividad en donde el mismo presta sus servicios".

${ }^{18}$ ERMIDA URIARTE, Oscar. "La intervención del Estado en las relaciones colectivas de trabajo latinoamericanas: situación actual y perspectivas" en el vol. Intervención y Autonomía en las Relaciones Colectivas de Trabajo. FCU. Mont. 1993, p. 379-390

19 VON POTOBSKY, Geraldo. Tendencias del Derecho del Trabajo. Crónica Internacional 1993 - 2002. El Derecho. Bs. As. 2004, p. 50 - 52 
en los últimos años los temas principales estuvieron centrados en el derecho de asociación de los funcionarios públicos, la protección de sindicatos, dirigentes y afiliados, la negociación colectiva y el derecho de huelga.

Así en Chile, por ley de 1994 se levantó la prohibición de sindicalización de funcionarios públicos y mediante otra reforma en 2001 se ampliaron los derechos de representación sindical a los fines de la negociación, restringiéndose la posibilidad de desvirtuar la negociación colectiva por grupos de trabajadores a través de contratos individuales múltiples o de adhesión a la oferta patronal, facilitándose además la negociación por sector de actividad. La libertad sindical ha sido todavía reforzada recientemente, mediante el cambio de "algunos aspectos de la actual regulación de las prácticas desleales y antisindicales, tanto a través de mecanismos estrictamente procesales, como del establecimiento de apremios y sanciones mas severos" ${ }^{20}$. Hubieron modificaciones tendientes a consagrar mayor protección de la actividad sindical en El Salvador (1994), Guatemala (2001) y Costa Rica (1993), que impidió en este caso a las asociaciones solidaristas intervenir en la negociación colectiva y los arreglos directos.

No obstante, el ejemplo de Costa Rica bien podría servir para demostrar que el progreso escrito de la norma no siempre se traduce en un efectivo avance en términos reales ${ }^{21}$.

20 GAZMURI RIVERos, Consuelo. " $E l$ fortalecimiento de la libertad sindical en la Ley 20.087”. Revista Laboral Chilena, núm. 145, abril 2006, p. 75

${ }^{21} \mathrm{Si}$ bien en la legislación de ese país los ámbitos de aplicación de los convenios colectivos y de los arreglos directos son excluyentes, como lo son los campos
En un estudio de la OIT sobre la reforma laboral en América Latina ${ }^{22}$ se concluye en referencia al derecho colectivo en que "el objetivo de la reforma pudo haber sido en ciertos casos fortalecer la posición de los trabajadores o de sus organizaciones, lo cual se observa sobre todo en el tratamiento de las relaciones colectivas de trabajo y en la búsqueda de una mayor autonomía colectiva. No obstante, en algunos de esos supuestos la práctica de individualización de las relaciones de trabajo y el repliegue del Estado han significado necesariamente una mayor desprotección de los trabajadores, lo que parece haber contrarrestado los avances de la legislación reformada en lo que a garantías sindicales y promoción de la negociación colectiva se refiere".

En el caso uruguayo, el sistema de relaciones laborales parece dirigirse hacia un modo de mayor intervencionismo estatal, lo cual ha provocado que muchos se interroguen si no se está produciendo un histórico viraje hacia la heteronomía en un sistema tradicionalmente definido como básicamente no regulado. La mutación se estaría produciendo no sin contradicciones, y

de acción de sindicatos y comités permanentes de trabajadores, en la práctica las asociaciones solidaristas han apoyado a los comités, con lo cual el número de arreglos ha superado largamente el de convenciones, lo que ha motivado que en este año 2006 la CEACR de la OIT formulara una observación individual, peticionando al Gobierno que "informe al respecto así como que se realice una investigación independiente sobre el elevado número de acuerdos directos con trabajadores no sindicalizados". Godínez Vargas, Alexander. Estudio Nacional sobre Negociación Colectiva, Diálogo Social y Participación en la Formación Profesional en Costa Rica. Cinterfor. 2006, inédito, p. 18

${ }^{22}$ VEGA RUÍZ, María Luz (ed.). La Reforma Laboral en América Latina: 15 años después. OIT. 2005. p. 71 
al socaire de un Gobierno con mayor cercanía al mundo sindical, lo cual plantea nuevos y complejos escenarios. Cabría preguntarse, además, si existe una dirección o un proyecto predeterminado, o se obra a impulsos de la coyuntura.

Son datos relevantes y síndromes de esta perspectiva, la convocatoria del Poder Ejecutivo a los Consejos de Salarios y el direccionamiento mismo del funcionamiento de estos organismos, que tienen mayoría estatal y que sujetan la negociación a ciertas "pautas" salariales impuestas heterónomamente; la regulación de las ocupaciones de los locales de trabajo y la protección judicial de la libertad sindical, junto a los esfuerzos por acordar en forma tripartita un marco jurídico para la negociación colectiva. La naturaleza dinámica e histórica (dependencia de los contextos) ya vista, no permiten definir con precisión la evolución mediata de este proceso, sino mas bien señalar su tendencia insinuada ${ }^{23}$.

Con todo, y al parecer casi sin proponérselo, se ha ido construyendo un modelo de relaciones laborales creado en forma aluvional, con normas autónomas y heterónomas de diverso nivel y que confluyen no siempre en forma pacífica.

Así en la regulación del conflicto el ordenamiento laboral infraconstitucional ha quedado conformado por las normas que limitan el ejercicio de la huelga y el lock out mediante la imposición de servicios esenciales, y el decreto referido a los modos de prevención y solución de conflictos (que reenvía a la autonomía colectiva) y

${ }^{23}$ BARRETTO GHIONE, Hugo. "Diálogo social, relaciones laborales y cambio político en el Uruguay: el consenso como problema” Inédito. 2006 regulación de las ocupaciones, todo lo cual comporta una especie de estatuto que presenta debilidades y cuestionamientos formales ${ }^{24}$, y que solo puede ser sostenible si se funda en una práctica conciliadora y mediadora del actor estatal (que quizá en el mediano plazo necesite de otros apoyos).

El carácter aluvional del modelo se aprecia mas claramente si observamos con detenimiento el desarrollo de la negociación colectiva. Si bien se ha destacado profusamente por la doctrina y los actores la necesidad de una ley marco de negociación, en la práctica la aplicación tan peculiar de la ley de Consejo de Salarios pone un nota de duda acerca de la posibilidad de un acuerdo social sobre el punto, y mas bien parece consolidarse un modelo de muy difusos alcances jurídicos pero de indudable eficacia práctica.

En puridad, es bien sabido que la ley núm. 10.449 no ha sido cumplida en las últimas dos convocatorias, y que en realidad lo que habilita y persigue su insuficiente "aplicación" es la consulta y negociación de los actores en la materia de fijación de los salarios mínimos, que en todo caso termina formalizándose mediante la envoltura del decreto del Poder Ejecutivo. A tal punto puede considerarse una práctica confusa, que los propios sujetos negociadores no aciertan en designar de modo unívoco los productos de la negociación, en tanto a veces se les llama "acuerdos" y a veces "convenios", pero siempre coinciden en recurrir a la

${ }^{24}$ BARRETto GHiOnE, Hugo. "Modos de producción del derecho y ordenamiento jurídico: una contribución al estudio de la regulación de los conflictos colectivos". En el vol. de las XVII Jornadas Uruguayas de Derecho del Trabajo y de la Seguridad Social, p. 307 
extensión mediante normas heterónomas dictadas en otro tiempo histórico, como la ley núm. 16.002. Así las cosas, existe una "negociación" de salarios mínimos que ni bien sobrepasa esa cota (incluyendo, por ejemplo, acuerdos en materia de licencias especiales), se expone a ser cuestionada en su legalidad (atento a que se funda en la potestad del Poder Ejecutivo de "dictar normas referentes a ingresos y, en particular, formular las categorías laborales y regular las remuneraciones de los trabajadores de la actividad privada", art. 1 lit. e. del Decreto Ley núm. 14.791); pero tampoco ese obstáculo ha impedido que progrese cierta negociación sobre las relaciones de trabajo en general. Ese funcionamiento parsimonioso y de precarios sostenes jurídico - formales, ha terminado por consolidarse si consideramos que su acta de nacimiento data de 1985 , cuando por primera vez el Poder Ejecutivo del momento optó por no aplicar la ley de Consejo de Salarios al no designar a los delegados de las partes de acuerdo al procedimiento electivo dispuesto en la norma legal.

Este aluvión de normas que terminan conformando a mi juicio un modelo básicamente heterónomo, en tanto:

- tanto la convocatoria a la negociación mal llamada "Consejo de Salarios" como la extensión de los acuerdos a todo el sector de actividad, reposan en normas heterónomas;

- el contenido de los acuerdos está determinado por "pautas" provenientes del Poder Ejecutivo, que ejerce así cierto control de la negociación;

- los contenidos de la negociación que se sitúen por fuera de la fijación de mínimos por categoría, se exponen a ser considerados como carentes de legitimidad jurídica.

Esta sugestiva heteronomía "a la uruguaya", no totalmente reconocida, no totalmente postulada, pero instalada $y$ vigente, puede convertirse en un escollo para la elaboración y acuerdo de una ley marco de negociación colectiva, en razón que los actores bien pueden considerar que no es del todo necesaria, pese al pertinaz discurso en contrario. Concretamente, la aplicación de este conjunto inorgánico de normas no sólo provee de un marco para la negociación, sino que permite, en definitiva, que la totalidad de la actividad privada tenga la oportunidad de negociar al socaire de un aparato legal que ha ido erigiéndose casi imperceptiblemente, con los espaciados aluviones normativos de 1943 (ley 10.449), 1978 (DL 14.791) y 1988 (ley 16.002). Asegurado ese nivel mínimo, queda todavía el escenario de la negociación colectiva autónoma propiamente dicha, complementario del nivel anterior, y que de darse las condiciones para su implantación (juego de poderes de los actores, etc), puede actuar y circular en el espacio negocial que pueda generar por sí misma. Así las cosas, cabe interrogarse cual es la ventaja que puede ganar el sistema delineado mediante una ley de negociación colectiva. De mantenerse el actual esquema, parece poco propicio como para generar expectativas de cambio.

\section{Institucionalización del sujeto sindical y judicialización del conflicto colectivo}

El cambio político producido en Uruguay en 2005 ha provocado una serie de 
modificaciones en las relaciones laborales, traducidos como ya se indicó, en un incentivo a la negociación colectiva en el sector público, una convocatoria a los mecanismos legales tradicionales de fijación de salarios mínimos mediante consejos tripartitos sectoriales, y el dictado de algunas normas de rango legal sobre protección a la actividad sindical y de rango reglamentario sobre derecho de huelga en su modalidad de ocupación de los locales de trabajo.

$\mathrm{Si}$ bien estas transformaciones no supusieron modificar la competencia material de la jurisdicción laboral, que continua ocupándose en exclusividad de los conflictos individuales de trabajo, algunas normas recientes y ciertas prácticas y estrategias de los actores del mundo del trabajo, que indujeron algunos pronunciamientos judiciales, parecen dirigirse a consagrar algún grado de judicialización de las relaciones colectivas, sin llegar a equipararse a la disciplina procesal brasileña, modificada recientemente por la Enmienda Constitucional núm. $45 .^{25}$

Son expresiones de esta tendencia, la participación del sindicato como sujeto activo de la relación procesal en la ley núm. 17.940, de enero de 2006, sobre protección de la actividad sindical ${ }^{26}$. En concreto, el numeral b.

${ }^{25}$ SAYÂO ROMITA, Arion. "Os novos instrumentos processuais à disposiçâo das partes em face da Emenda Constitucional núm. 45”. Revista do Tribunal Regional do Trabalho $16^{\circ}$ Regiâo. Sâo Luís. V. 14 núm. 1. Dic. 2004, p. 30

${ }^{26}$ La norma prescribe la nulidad de todo acto antisindical, imponiendo la reinstalación o reposición del trabajador y creando dos procedimientos diversos del art. 3 dispone que "en los procedimientos a que se refiere el artículo 2 de la presente ley, la legitimación activa corresponderá al trabajador actuando conjuntamente con su organización sindical”.

La norma supone un grado de institucionalización del conflicto y del sujeto sindical antes desconocido y aún difícil de imaginar en el paisaje liberal-abstencionista del derecho colectivo uruguayo. Parte de la doctrina ha reaccionado considerando inconstitucional la conformación de la legitimación activa ${ }^{27}$, o reconociendo que se traduce en una "restricción del derecho del trabajador" 28 , o aún leyendo la regla en el sentido de consagrar un litisconsorcio facultativo ${ }^{29}$.

En estemismomarcodeinstitucionalización sindical debe apreciarse: a) la legitimación de las ocupaciones del lugar de trabajo como conducta permitida (y aún derecho) de los trabajadores; y b) la facultad de la Administración del trabajo de justipreciar la representatividad sindical.

La referencia al Dec. 165/06 no es para ingresar al debate tradicional y nuevo sobre

en atención a la naturaleza de la actividad sindical desempeñada por el eventual reclamante. Asimismo, establece cláusulas sindicales como la retención de la cuota y facilidades para el ejercicio de la actividad sindical (comunicaciones en la empresa, licencia, etc).

${ }^{27}$ RASO DELGUE, Juan. “ ¿Es constitucional el lit. $B$ del art. $3^{\circ}$ de la Ley 17.940?”. En el vol. XVII Jornadas Uruguayas de Derecho del Trabajo y de la Seguridad Social. FCU. 2006, p. 173

28 TOMMASINO, Beatriz. “Aspectos procesales de la ley 17.940”, en Mantero de San Vicente, Osvaldo y otros, Protección y promoción de la libertad sindical. Curso sobre la ley 17.940, FCU, 2006, p. 139

29 SARTHOU, Helios. "Siete tópicos sobre la tuitividad sindical en la ley 19.740”, en el vol. Protección y promoción.. cit. p. 188 
la pertenencia de esta acción gremial al derecho de huelga, aspecto que recientemente ha motivado una fuerte polémica en la doctrina uruguaya ${ }^{30}$, sino para destacar el encuadramiento sindical dentro de los márgenes de la heteronomía, receptado con total cristalinidad en el art. $4^{\circ}$ lit. b del decreto, que establece como uno de los requisitos de la ocupación, la asunción de ciertas responsabilidades a cargo de "la organización mas representativa de los trabajadores ocupantes" 31 . Parece claro que la disposición permite a la Administración del trabajo justipreciar la representatividad sindical, elemento que antaño sólo había sido acudido por el legislador en forma excepcional al reglamentar la existencia de más de una organización sindical en caso de negociación colectiva (art. $1^{\circ}$ de la ley núm. 13.556).

${ }^{30} \mathrm{Al}$ respecto pueden consultarse las distintas posiciones de la doctrina uruguaya y aún los matices existentes entre las mas cercanas: Oscar Ermida Uriarte "Ocupaciones y solución de conflictos colectivos"; Alvaro Rodríguez Azcúe "Breve historia de la conflictividad laboral en Uruguay”; Eduardo Ameglio "La regulación de las relaciones colectivas de trabajo: por el camino equivocado"; H. Barretto Ghione "Modos de producción del derecho y ordenamiento jurídico: una contribución al estudio de la regulación de los conflictos colectivos"; Natalia Colotuzzo "Ocupación de los lugares de trabajo: estudio y evolución de este fenómeno"; Jorge Ubaldo Seré "La ocupación de lugares de trabajo y el Decreto 165/06”; Nelson Larrañaga "Ilicitud de la ocupación del lugar de trabajo" y otros, publicados en el vol. XVII Jornadas Uruguayas de Derecho del Trabajo y de la Seguridad Social, cit.

${ }^{31}$ En concreto, dice el art. $4^{\circ}$ lit. b) que "La organización sindical más representativa de los trabajadores ocupantes, deberá adoptar las medidas que considere apropiadas para prevenir daños en las instalaciones, maquinarias, equipos y bienes de la empresa o de terceros, así como aquellas destinadas a prevenir o corregir de forma inmediata, en caso de producirse, actos de violencia".
Retomando el eje del discurso sobre la legitimación activa en caso de ejercer la pretensión ante la discriminación antisindical, el tema presenta algunas peculiaridades interpretativas que es preciso estudiar. En primer término, resulta evidente que el liberal b) del art. $3^{\circ}$ prescribe la necesidad de comparecer en conjunto el trabajador y la organización sindical.

Ambos son titulares del derecho de la libertad sindical, y si bien es teóricamente posible distinguir la titularidad de un derecho (como relación sustantiva), de la acción procesal (dada la autonomía e independencia de la legitimación procesal) en el caso se da una coincidencia o correlación entre la categoría de los sujetos activos del derecho y de la acción.

Esa comparecencia conjunta, ese paralelismo en la titularidad del derecho y de la acción se traduce en el litisconsorcio activo necesario del art. $3^{\circ}$ lit. b. Siendo la libertad sindical un valor o principio que ontológicamente se vincula a la persona del trabajador y al colectivo que representa el interés común de la categoría, parece coherente determinar que la comparecencia en juicio, el ejercicio de la pretensión, y las consecuencias en el plano de la decisión judicial, deba comprender y vincular en forma inescindible a ambos sujetos. Se establece una dependencia entre el sujeto individual y el colectivo que termina por sellar y asegurar la eficacia de los bienes jurídicos comprometidos, evitando que la dispersión de soluciones en las diversas vías procesales (jurisdiccionales, administrativas, autónomas, etc) resten coherencia al sistema, entre otras cosas, por la eventual bifurcación de soluciones que puedan adoptar los 
titulares de la libertad sindical en sede de "transacciones" económicas en el nivel individual que resultan contraindicadas para asegurar la efectividad del derecho a la actividad sindical.

Sobre el punto, conviene detenerse en dos aspectos que resultan fuertemente renovadores para el derecho procesal uruguayo, tan falto de una disciplina propia que dé cuenta del particularismo del derecho del trabajo.

En primer término, el litisconsorcio activo determina la imposibilidad de poner fin al proceso mediante una transacción de tipo patrimonial, dada la falta de capacidad del sujeto activo, en su compleja composición, para disponer derechos de una esfera que le es parcialmente ajena. En concreto, la ingeniería de los dispositivos procesales de la ley no conciben un resultado diverso que el acogimiento o rechazo de la pretensión de reinstalación o reposición; la solución patrimonial (en sede transaccional) está excluida en atención a la materialidad de los derechos objeto de protección y a la existencia misma del litisconsorcio necesario. Esta estricta e inevitable circunscripción de técnicas procesales específicas creadas para cumplir efectivamente con la protección del derecho a la libertad sindical, deja sin posibilidad la recurrencia por estas vías al consabido recurso de la "patrimonialización" del daño a la libertad sindical. En esta dirección, se ha dicho que "en lo que refiere a las consecuencias de la actuación unívoca, debe estarse a la naturaleza de los actos procesales cumplidos o a cumplirse. Si se trata de actos procesales útiles, tendientes a la preservación del derecho, el acto cumplido por uno sólo de los litisconsortes aprovecha a todos (...) en cambio, cuando se trata de actos procesales de naturaleza abdicativos o extintivos, deben provenir de todos los integrantes de la parte compleja litisconsorcial. A título de ejemplo, el allanamiento, el desistimiento, la transacción"32.

El sujeto colectivo que concurre con su voluntad a conformar el litisconsorcio activo genera también una serie de perplejidades en un derecho procesal pertinazmente refractario a reconocer las discontinuidades y particularidades del conflicto capital/ trabajo. En concreto, la comparecencia de la organización sindical en juicio parece convocar al demonio para ciertos espíritus formalistas, aunque quizá deba reconocerse que la ley extremó la solución cuando impuso la conformación del litisconsorcio necesario en lugar del facultativo ${ }^{33}$.

Por otra parte, admitido ello, se plantean un par de cuestiones sobre las que vale la pena reflexionar. Se trata en primer término de desestimar la interpretación de que al referir a "su" organización sindical la ley esté exigiendo la comparecencia del sindicato de empresa. Ello por dos razones:

a) en algunos casos, previstos en la propia norma, de inexistencia de organización sindical de empresa (art. $1^{\mathrm{o}}$ in fine) haría imposible la conformación del litisconsorcio;

b) por otra parte, teniendo en cuenta que los trabajadores "tienen el derecho de

32 TOMMASINO, ob cit, p. 139

${ }^{33}$ La norma supone además una serie de desafíos para la jurisdicción laboral, que demandará "una actividad jurisdiccional mucho mas compleja que la habitual de creación de la regla especial adaptada al caso concreto". ROSSI, Rosina. "La nueva tutela de la libertad sindical: un reto a la judicatura laboral”. Rev. Derecho Laboral. T. XLIX n ú m. 222, p. 377 
constituir las organizaciones que estimen convenientes, así como el de afiliarse a estas organizaciones" (art. $2^{\circ}$ Convenio Internacional núm. 87), la organización y el encuadramiento sindical es absolutamente libre, a tal extremo, que es habitual que los trabajadores se organicen en sindicatos de empresa y posteriormente en sindicatos de segundo grado, o aún en sindicatos únicos de actividad (caso de metalúrgicos, construcción, etc).

En todos los casos se trata de "su" sindicato: el de empresa, el de nivel federal, y el sindicato único de la actividad, y en consecuencia una interpretación que limitara o permitiera la comparecencia únicamente del sindicato de empresa quedaría en el vacío, sin sustento real, por desconocer el dato social que pretende normar, y aún violentando las normas del propio convenio internacional.

Otro aspecto digno de consideración radica en atestiguar que dado el tenor del texto legal, no es menester que el sindicato cuente con personería jurídica para comparecer en juicio ${ }^{34}$.

En efecto, nótese que la ley refiere a la "organización" sindical, y no a la “asociación”, locución ésta que denota mayor formalidad y permanencia. El término “organización" reenvía a la noción de la

${ }^{34}$ Así se ha pronunciado la doctrina laboral que ha estudiado el punto. LOUSTAUNAU, Nelson. "Litisconsorcio necesario en las acciones creadas por la Ley 17.940 y limitación al derecho constitucional de accionar”, y GOLDSTEIN, Eduardo. “Legitimación procesal de las organizaciones sindicales para promover las acciones del art. $2^{\circ}$ de la Ley No 17.940 del 02.01.06”, ERMIDA FERNÁNDEZ, Martín. "Aspectos procesales de la Ley 17.940”, todos en el vol. cit. de las XVIII Jornadas Uruguayas, p. 149191 y 237 experiencia social, campo en el cual es de toda evidencia que los sindicatos no cuentan con personería jurídica para actuar en el ámbito del mundo del trabajo.

Otra significativa manera de judicializar el conflicto colectivo se ha dado en algunos casos en que la estrategia de los actores traspuso la frontera y pretendió acudir a soluciones procesales para poner fin a ocupaciones de locales de trabajo.

En este punto, los mecanismos ensayados han sido la acción de amparo, las medidas precautorias y aún la denuncia penal.

La acción de amparo para provocar la desocupación de los locales de trabajo había sido inapropiada por entenderse improcedente desde el punto de vista de la competencia material de la jurisdicción laboral o por no surgir claramente la ilegitimidad de la medida de ocupación, en asuntos que habían sido promovidos por los titulares de la explotación y por trabajadores que no adherían a la medida y se veían impedidos de acceder al lugar de trabajo.

En un caso sometido a decisión judicial ${ }^{35}$, la Sede expresó que "nos encontramos ante un conflicto entre trabajadores que al no poder solucionarlo entre ellos acuden a la justicia como vía de solución. No es éste el ámbito para la discusión de este tipo de conflictos". Y agrega que ante la falta de acuerdo doctrinario sobre calificación de derecho o medida ilegítima, "la decisora se inclina por considerar que no se da en el caso de autos la nota de ilegitimidad manifiesta requerida en la ley para que pueda prosperar

${ }^{35}$ Sentencia núm. 35 de 4 de mayo de 2004, dictada por la Juez Letrado de Primera Instancia de Lavalleja de $2^{\circ}$ turno. 
la acción de amparo, razón por la cual desestimará la misma”.

No obstante, una reciente sentencia ${ }^{36}$ confirmada en segunda instancia, ha calificado a la ocupación como una medida ilegítima y lesiva de la libertad de trabajo y del derecho de propiedad. En el caso, la acción fue promovida por un conjunto de trabajadores no sindicalizados opuestos a la medida de acción gremial de ocupación dispuesta por el sindicato de empresa.

La sentencia oscila entre un extremo de considerar que la ocupación no tiene sustento normativo expreso y que resulta lesiva de derechos constitucionales, y por otro lado, en argumentar que dado que se tomó sin cumplir los requisitos establecidos en el dec. 165/06 (acudir a la negociación y mediación del Ministerio de Trabajo o el Consejo de Salarios) la medida padece de "cierta" ilegitimidad. Por otra parte, la Sede funda su decisión de proceder a la desocupación en una norma como el art. $6^{\circ}$ del Dec. 165/06 que atribuye esa facultad únicamente al Ministerio de Trabajo.

En segunda instancia ${ }^{37}$, se morigeran algunas de las aristas mas filosas de la argumentación referida a la calificación como ilegítima de la conducta de los huelguistas, insistiendo en aspectos procedimentales, como "la forma intempestiva de adopción de la medida, sin dar siquiera noticia o habilitar la posibilidad de diálogo con los empleadores, teniendo en cuenta que sólo se

${ }^{36}$ Sentencia núm. 59 del 21 de setiembre de 2006 dictada por el Juzgado Letrado de Primera Instancia en lo Civil de $5^{\circ}$ turno.

${ }^{37}$ Sentencia núm. 159 de 6 de octubre de 2006, dictada por el Tribunal de Apelaciones en lo Civil de $5^{\circ}$ turno. había avisado de que se comenzaría a trabajar a reglamento". La sentencia refiere también al número de ocupantes, muy menor respecto del total de los afiliados, y de los demandantes de la acción de amparo.

Estos vaivenes en los criterios acerca de la legitimidad de la ocupación y en los fundamentos de las decisiones judiciales constituyen síntomas de la evidente dificultad que tiene la magistratura para entender en asuntos que no deberían ser ventilados judicialmente, en tanto no tienen que ver con cuestiones de derecho sino de mero interés, mas propio de dilucidar en otros ámbitos.

Pero lo que el pronunciamiento hizo fue ocupar el espacio de la heteroregulación que no había sido asumido por la Administración del trabajo cuando reglamentó en forma inadecuada en el dec. 165/06 la modalidad de ocupación de los lugares de trabajo. Es por ello que, más allá de las consideraciones jurídicas, la actividad judicial se presenta como una alternativa y una respuesta del orden jurídico con perfil propio.

En otro caso, la justicia penal ${ }^{38}$ decretó el procesamiento con prisión por el delito de apropiación indebida a un grupo de trabajadores que ocupaba una planta industrial y había constituido una cooperativa para explotar la empresa por entender que existió abandono del empresario.

Paradojalmente, la sentencia tiene un costado laboral sorprendente, en tanto dice que "en ejercicio del derecho de huelga, la ley les permite a los trabajadores ocupar la empresa y tomar la posesión de los bienes muebles de la misma, con la obligación de

\footnotetext{
${ }^{38}$ Sentencia de fecha 9 de marzo de 2006 del Juzgado Letrado en lo Penal de $4^{\circ}$ turno
} 
preservarlos y restituirlos al propietario una vez finalizado el conflicto. Pero en la especie, los indiciados una vez que tomaron posesión de los bienes muebles de la empresa ocupada, se apoderaron de los mismos convirtiéndolos en su provecho".

La sentencia "Vanni" comportó - otra vez - un límite heterónomo al conflicto, constituyéndose en un sucedáneo obligado ante lo que se entendía como cierto vacío normativo. A tal punto, que muy luego la Administración "reaccionó" mediante una normativa que recogió el contenido material de la prescripción judicial, al prohibir en el lit. d) del art. $4^{\circ}$ del dec. 165/06 que los ocupantes asuman "el giro o funcionamiento normal de la empresa, salvo en aquellos casos en que el empleador haya abandonado la explotación o no tenga representante en el país".

\section{El problema de la tensión entre la directiva constitucional de promoción sindical y las libertades individuales: la importancia de distinguir las procedencias y los ámbitos de aplicación}

La llamada libertad sindical negativa no tiene reconocimiento en el Convenio Internacional núm. 87 y el Comité de Liberad Sindical ha dicho, a lo sumo, que "una legislación que establece el derecho a no sindicarse o a no permanecer en un sindicato no constituye en sí una violación de los Convenios núms. 87 y 98"39.

\footnotetext{
${ }^{39}$ La Libertad Sindical. Recopilación de decisiones y principios del Comité de Libertad Sindical del Consejo de Administración de la OIT. 4 ed (revisada), núm. 329
}

Al respecto pueden señalarse algunas zonas de colisión de derechos individuales y colectivos que han sido objeto de infrecuente polémica en Uruguay hasta hace poco tiempo atrás.

d.1) Afectación del derecho de propiedad y del derecho al trabajo a causa del ejercicio del derecho de huelga en la modalidad de ocupación de los lugares de trabajo.

Se parte en este caso de la posición de la doctrina mayoritaria de considerar la ocupación como una modalidad del derecho de huelga, en tanto no existe definición legal que pueda recortar o limitar el fenómeno, por lo cual no existirían límites internos ${ }^{40}$. La ausencia de una definición legal conduce a concebir la huelga de acuerdo al uso que de la misma hagan los actores, construcción que ha sido receptada por la jurisprudencia, según acaba de verse.

Estrictamente, no hay ocupación sin huelga porque en realidad se trata de una misma realidad, caracterizada de acuerdo a los criterios mas tradicionales como la abstención colectiva de tareas con una finalidad de protesta o reclamo. Cuando se abandona esa actitud pasiva que la ocupación comparte con la huelga, se puede producir la penalización de las conductas, según quedó visto en el caso penal indicado supra.

En la hipótesis de ocupación de los lugares de trabajo no es de recibo aducir que existe una colisión actuante de derechos ${ }^{41}$.

${ }^{40}$ MANTERO, Ricardo. Los Límites de la Huelga. A. Fernández. 1992

${ }^{41}$ ERMIDA URIARTE, Oscar. "Ocupaciones y solución de conflictos colectivos: aproximación al Decreto 165/06 de 30 de mayo de 2006”. Rev. Derecho 
En principio, no hay desconocimiento alguno del derecho de propiedad, que por otra parte no puede considerarse como absoluto y por tanto puede ser objeto de limitación por afectar la esfera de otros derechos. Quien ocupa no lo hace con ánimo de dueño, sino que se trata de una medida de acción gremial enmarcada en una controversia con el empleador en la que la titularidad del bien no se encuentra en discusión.

La ponderación de derechos, si cabe, debe circular en el ámbito del reconocimiento de la licitud de la medida de ocupación, por un lado, y en la limitación temporal del uso absoluto de los bienes comprometidos por parte del empleador por el otro.

Tampoco existe un desconocimiento del derecho al trabajo de los no adherentes. En principio, resulta un problema de mayor y mas vasta envergadura teórica determinar si existe un derecho al trabajo, que demandaría, por ejemplo, la identificación de un sujeto pasivo de ese derecho, que estaría obligado a proporcionar un empleo, implementar políticas activas, servicios de colocación, limitar la facultad de despedir incausada, etc. El derecho al trabajo se desplegaría, entonces, en una serie de obligaciones de diversos sujetos, entre los cuales el empleador operaría como deudor directo de ciertos comportamientos vinculados a la conservación de la relación de trabajo, la justificación - y limitación - del despido, la promoción y el ascenso, etc. Se trata por tanto de una cuestión hartamente dificultosa y debatida, que por otra parte, de aceptarse,

Laboral, T. XLIX, núm. 222, p. 467. Del mismo autor, su ponencia en las XVIII Jornadas Uruguayas de Derecho del Trabajo y la Seguridad Social. quizá haría que rápidamente quienes hoy postulan la existencia de ese derecho virarían a posiciones mas restrictivas, o fueran menos entusiastas en la defensa de un pretendido derecho al trabajo.

Reducir por tanto el pretendido derecho al trabajo a la sola expresión de fundar una pretensión de desocupación de los locales de trabajo en caso de huelga, significaría empobrecer las dimensiones de un problema del derecho del trabajo de extraordinario alcance y que continúa siendo un a materia pendiente de mayores esfuerzos teóricos.

d.2) La renovada tensión entre el derecho a no discriminación y las cláusulas sindicales. Un lugar para la libertad sindical negativa

El Comité de Libertad Sindical ha tomado cierta distancia del debate sobre las cláusulas sindicales.

Ha dicho, en términos generales, que "los problemas relacionados con las cláusulas de seguridad sindical deben resolverse a nivel nacional, de acuerdo con la práctica y el sistema de relaciones laborales de cada país. En otros términos, tanto aquellas situaciones en que las cláusulas de seguridad sindical están autorizadas como aquellas en que están prohibidas, se pueden considerar conformes con los principios y normas de la OIT en materia de libertad sindical" ${ }^{42}$.

La prescripción por fuente legal de cláusulas sindicales como la retención obligatoria de la cuota sindical ("check off") ha levantado resistencias en el sector empleador en el debate de la reciente ley

\footnotetext{
${ }^{42}$ La Libertad Sindical cit. núm. 323
} 
de protección y promoción de la actividad sindical núm. 17.940.

Con todo, el problema central en este punto es la ubicación de la llamada "libertad sindical negativa", que debe ser sin duda reconocida como posibilidad "de expresión del disenso, como es el ejercicio de la libertad de no afiliarse o de afiliarse a otra organización"43. El punto no radica en desconocer esa básica opción individual de afiliarse o no al sindicato (visión estática), sino en la dimensión diacrónica de los derechos, o sea, en la eventual colisión con la actividad sindical propiamente dicha y los derechos sindicales actuantes. Parte de la doctrina vincula la libertad sindical negativa con la "agresión" 44 que sindicatos y trabajadores pueden producir a la libertad sindical, en lo que parece un exceso de equiparación de derechos de naturaleza y procedencia bien diversa, según se verá en adelante.

Fue en caso jurisprudencial reciente ${ }^{45}$ donde se planteó como conducta discriminatoria la preferencia otorgada al personal sindicalizado para el reingreso a la actividad laboral ante la reapertura de una entidad bancaria. El actor reclamó que no se respetaran criterios de selección de los empleados basados en la objetividad, transparencia y no discriminación, en

${ }^{43}$ RASO DELGUE, Juan. “Ley $N^{o} 17.940$ sobre promoción y protección de la libertad sindical: análisis de los aspectos sustantivos". En el vol. de las XVII Jornadas de Derecho del Trabajo y la Seguridad Social, p. 17

${ }^{44}$ CASTELLO, Alejandro. "Apuntes sobre la noción de acto antisindical y su régimen de nulidad absoluta”. En el vol. de las XVII Jornadas de Derecho del Trabajo y la Seguridad Social, p. 76

${ }^{45}$ Sentencia núm. 48/2006 del 20 de junio del 2006 dictada por el Juzgado Letrado de Primera Instancia de Trabajo de 8vo. Turno. tanto se habría seleccionado la mayoría del personal por el sólo hecho de pertenecer a los cuadros sindicales, fruto de un acuerdo con el sindicato. El caso no llegó a significar una imposición de afiliación para obtener un empleo, ya que se trataba de un acuerdo que determinaba la incorporación de trabajadores sindicalizados en un importante porcentaje, pero sin excluir a los no sindicalizados, luego de un proceso de cierre y apertura de una entidad bancaria.

La sentencia no refiere a la libertad sindical negativa en ningún momento, ni al derecho de los trabajadores a no afiliarse al sindicato o a desafiliarse ${ }^{46}$; simplemente sitúa el problema en el derecho a la no discriminación (por no estar afiliado al sindicato). Tampoco menciona la violación al derecho positivo vigente respecto del derecho a la no sindicalización (dec. 93/68, Declaración Sociolaboral del MERCOSUR).

Contrariamente, el Comité de Libertad Sindical ha entendido que existe una discriminación injusta solo si se establecieran "condiciones irrazonables para la afiliación de las personas que la soliciten" 47

Tanto las cláusulas de retención de las cotizaciones como las de preferencia tienden a admitirse como lícitas ${ }^{48}$, en tanto suponen el cumplimiento constitucional de la promoción de sindicatos, y no limitan la libertad y el derecho de los no afiliados, en razón que:

${ }^{46}$ Se deja expresa constancia que muchas de las referencias y comentarios a la sentencia fueron tomados del trabajo inédito de la Dra. Beatriz Durán, a quien se agradece la generosidad y diligencia en proporcionar dicho material en tiempo perentorio.

${ }^{47}$ La Libertad Sindical cit. núm. 330

${ }^{48}$ ERMIDA URIARTE, Oscar. Sindicatos en Libertad Sindical. FCU. 1985. p. 34-35 
- en el caso de la retención de la cuota sindical, solo comprende a los afiliados, a diferencia de otras soluciones del derecho comparado;

- en el caso de la preferencia, se establece solo un criterio de supremacía no excluyente.

En todo caso, la tensión entre la libertad sindical entendida como derecho del colectivo de trabajadores y como derecho "positivo", y la libertad sindical en su dimensión individual, "negativa", genera otra serie de problemas.

En puridad, la llamada libertad sindical negativa debe enmarcarse en el derecho mas general de la libertad de trabajo y no en la esfera mas propia del estatuto Constitucional del trabajo, contenido en las normas de los arts. 53, 54 y 57 que prescriben la protección especial y la promoción del sindicalismo, y en el Convenio Internacional núm. 87, que no hace mención a la zona de las libertades individuales a no afiliarse.

El juego de los derechos se sitúa en dos zonas diversas del ordenamiento constitucional, con consecuencias al conjunto normativo infraconstitucional y a las prácticas jurídicas.

Por un lado, el derecho liberal clásico postula la libertad de trabajo, por oposición a todo tipo de impostura proveniente de la rémora corporativa, conquista debida a la explosión de libertades que desencadenó la revolución francesa; pero por otro lado, en el sector propio del ordenamiento referido al trabajo subordinado, producto de una evolución de las ideas jurídicas (y por tanto, surgidas en un momento cronológicamente posterior), el elenco de los derechos positivados inclina su peso mayormente hacia el derecho de sindicación.

Las referencias marginales a la libertad sindical negativa en el ordenamiento infraconstitucional se ubicaban a nivel reglamentario (dec. 93/68) hasta la adopción de la Declaración Sociolaboral del Mercosur. Sin embargo, ambos derechos no resultan equivalentes y tienen un diverso "peso" (al decir de Dworkin) como para sostener una ponderación de derechos:

- la libertad sindical negativa no integra el elenco de los derechos a la libertad sindical del CIT núm. 87;

- queda fuera del marco de los derechos laborales de los arts. 53 y siguientes de la Constitución, que dotan y marcan directivas al ordenamiento inferior y sientan las bases del derecho sindical y su fomento (art. 57).

El derecho de no afiliarse queda así cristalizado como libertad en un ámbito de mayor generalidad y por fuera de esa esfera propia y singular de los derechos individuales y colectivos del trabajo subordinado, debiendo por tanto interpretarse e integrarse con mayor precaución para la apreciación de eventuales colisiones de derechos.

El juego de preponderancias de los derechos que viene desarrollándose bien podría verse alterado en caso que ciertas medidas como la ocupación, fueran adoptadas por una minoría de trabajadores, en tanto podría cuestionarse su legitimidad y representatividad colectiva, aspectos insinuados y hasta ahora nunca aplicados en el lit. b) del art. $4^{\circ}$ del dec. 165/06. 
E) La opacidad de la interpretación de las normas jurídicas como espacio de contradicción

La sanción de la ley núm. 17.940 dejó atrás definitivamente la arraigada interpretación del art. 1 del CIT núm. 98, que lo consideraba meramente programático e inhábil para provocar la reinstalación del trabajador despedido por motivos sindicales.

El recurrido argumento consistió en sostener que no existía una norma laboral/ legal habilitante, y por tanto no correspondía otra cosa que acudir a la fuente eterna del derecho común gracias a la que fue posible construir la figura del abuso en el "derecho" de despedir (existieron otras formulaciones doctrinarias que negaban la existencia de tal derecho, pero ahora no es del caso dar cuenta de las mismas).

El monolítico consenso operó a través de lo que Romagnoli llamó la "exasperada autorreferencialidad del derecho" o sea, la creencia de que "todo está ya previsto y escrito en el libro de la perenne sabiduría de los romanos" $" 49$.

El equívoco, la inercia, no comportó un error pequeño ni pasajero, sino que se trató del desconocimiento de la radical novedad que significa la libertad sindical en el elenco de derechos de las personas, una especie de contrapoder en una sociedad diferenciada y pluralista.

Los gobiernos adujeron argumentaciones similares en sus explicaciones a la Comisión de Expertos en Aplicación de Convenios y Recomendaciones o al Comité de Libertad

${ }^{49}$ ROMAGNOLI, Umberto. "La libertad sindical, hoy”. Revista Derecho Social. Núm. 14, 2001, p. 9
Sindical de la OIT: "el reintegro - dijeron no se ha aplicado como sanción en caso de despidos antisindicales debido a la falta de base normativa para exigirlo".

Esta forma de interpretar el derecho creyó ver un vacío normativo, y recurrió a las soluciones que tenía a la altura de la vista, de tipo legal, sin reparar en la dirección normativa que venía ordenada por las normas de superior jerarquía, y aún sin considerar que era posible admitir la nulidad de lo actuado frente a la violación de una norma prohibitiva sin necesidad de norma expresa habilitante, dado que la nulidad es un concepto lógico antes que una figura legal de enumeración taxativa.

En razón de estas vicisitudes interpretativas, la ley núm. 17.940 aplica un sugestivo blindaje ante cualquier fuga del sentido protector: el art. 1 y el art. 3 lit. a y c imponen el reintegro o reinstalación.

En definitiva, si algo demuestra la reiteración de la apelación a la reinstalación en la ley núm. 17.940 (arts. $1^{\text {o y }} 3^{\text {o }}$ lit. a), es que para interpretar, mas que atenerse a los límites de lo legal, se debe integrar el conjunto de principios, valores y métodos del ordenamiento jurídico, y en esta línea, es la Constitución y son los Derechos Fundamentales los que reconstruyen y prestan unidad al sistema jurídico.

No fue ese el camino seguido por la jurisprudencia que leyó el CIT como meramente programático. La interpretación judicial como actividad mediadora entre el texto legal y la norma (entendida como regla aplicable al caso concreto) se comportó así como uno de los componentes centrales del modelo de relaciones colectivas de trabajo en Uruguay: la debilidad de la protección acordada a una actividad sindical que en 
otras expresiones gozaba de una libertad no conocida en el derecho comparado latinoamericano. Curiosa y eminente responsabilidad la de la interpretación normativa: constituir un pilar sobre el que se asienta el derecho colectivo.

El modelo acordaba amplios márgenes de libertad sindical para organizar y autodeterminarse; pero a la vez, esa libertad sindical presentaba un déficit sustantivo en la faz de protección a la actividad sindical.

Ese estado de cosas resulta aleccionador en un doble sentido:

- por un lado, señala la necesidad de receptar una interpretación del derecho del trabajo que no se recluya en los límites del derecho legal, y se abra a la consideración de las normas que imprimen un sentido al ordenamiento;

- en segundo término, esta aparente antinomia de la libertad sindical en nuestro modelo, fruto de una interpretación de un juego normativo infraconstitucional, reafirma la complejidad del ordenamiento jurídico laboral, porque como dice Tarello: "el derecho sindical es un derecho que presenta una particularidad, precisamente, la de parecer creado incluso conscientemente - por los juristas y por los jueces además de, a menudo inconscientemente, por la práctica sindical; y de no aparecer creado, sino en una pequeña medida, por el legislador" ${ }^{50}$.

No es de esperar un efecto automático de la norma aprobada: incidirán diversos factores y procesos, en los cuales la distribución del poder y las concepciones de cultura

50 TARELLO, Giovanni. Teorías e Ideologías en Derecho Sindical. Comares. Granada. 2002 jurídica influirán decisivamente. No obstante, mediante el dispositivo del art. 1 y 3 lit. a y c. la norma reconcilia la interacción doctrina/ jurisprudencia/prácticas administrativas, desavenidas a partir de las distintas miradas que tuvieron: la doctrina se inclinó por entender procedente la reinstalación, y la jurisprudencia y administración solo condescendieron hacia una muchas veces módica, indemnización o sanción pecuniaria al infractor de la libertad sindical.

Cabe preguntarse todavía sobre la índole de las novedades que aporta la ley:

- la positivización (la necesidad del derecho, de que hablaba Alexy $\left.{ }^{51}\right) \gtreqless$ integra el derecho a no ser discriminado sindicalmente al elenco mas general de actos que afectan la igualdad de tratamiento de las personas?

Hay una avanzada en el derecho contemporáneo de salvaguardar la igualdad de tratamiento de las personas, asegurando la diferencia, la diversidad. Sin embargo, la ley núm. 17.940 protege la igualdad de las personas en otra dimensión, ya que se dirige a prohibir aquellos actos discriminatorios que agravan la diferenciación material y estructural de los sujetos del derecho del trabajo. Quiere decirse que la norma procura reparar aquella discriminación que opera en el sentido de profundizar y agravar la hiposuficiencia e impedir la autonomía de uno de los sujetos de la relación laboral;

- pero ¿ es la nulidad y reinstalación el cambio sustantivo de la ley?.

Es posible pensar que el cambio radica en la conducta que es dable esperar del

51 ALEXY, Robert. Teoría del Discurso y Derechos Humanos. Univ. Externado de Colombia. 1995 
empleador: tendría ahora la carga e intensidad de justificar los despidos u otros actos que asuma en el ejercicio de su poder de dirección, si no quiere sufrir una consecuencia mas gravosa y compleja. La ley compone un intersticio por donde puede colarse la justificación de los despidos ingresando así en una línea afín a los desarrollos del Convenio Internacional núm. 158.

Hay por tanto una mayor limitación en el poder de dirección: el patrono deberá justificar si no quiere verse expuesto a un litigio, y una vez sometido a la jurisdicción, debe también ejercer una actividad conducente a justificar sus decisiones.

\section{CONSIDERACIONES FINALES}

Estudiar el derecho colectivo "en tránsito" comporta una doble dificultad: primero, de encontrar los elementos de permanencia, que estructuren la materia; segundo, aventar el riesgo de que la dinámica de los hechos sociales producidos en procesos de cambio hagan que rápidamente algunas consideraciones queden obsoletas.

Con todo, pueden esbozarse algunas conclusiones.

Parece irse delineando cierta judicialización del conflicto colectivo, que encontró en la pretensión plurisubjetiva de trabajadores que defienden su derecho "al" trabajo un sucedáneo para situarlo con eficacia en la jurisdicción (laboral o civil, cuestión todavía no totalmente resuelta).

Una primera aproximación interpretativa a este fenómeno indicaría que la falta de mecanismos preventivos y de conciliación eficientes en el ámbito de la Administración del Trabajo ha provocado que aparezca casi subsidiariamente la alternativa judicial para dar solución a los conflictos colectivos, con las dificultades que tal estrategia supone para el aparato judicial.

Ese profundo proceso ocurre sin que se altere el cuadro normativo del derecho positivo, que continua mirando, como si nada pasara, al paisaje incontaminado del art. 106 de la ley núm. 12.803 que prescribe la competencia de la justicia laboral para los casos de conflictos individuales de trabajo ${ }^{52}$.

En otro orden, la nueva dinámica sindical desatada a partir de la convocatoria de los Consejos de Salarios y de la legislación "de soporte" de la ley núm. 17.940 ha provocado la emergencia de temas que parecían definitivamente lejanos de toda actualidad en derecho colectivo, y cuya enseñanza universitaria se había rutinizado: me refiero a las cláusulas sindicales, que cobraron relevancia a partir de los debates sobre la imposición legal del descuento de la cuota sindical y de ciertos pronunciamientos sobre preferencias. En el caso de la libertad sindical negativa, justo es apreciar su potencialidad para circular en el ámbito de las libertades individuales como derecho a no afiliarse o desafiliarse, pero sin embargo su ubicación en el rango de las libertades

${ }^{52}$ La competencia de los Juzgados Laborales en cuestiones de discriminación a la actividad sindical (art. 3 lit. D de la ley 17.940) introduce una nueva vertiente de problemas a esta cuestión, entre otras cosas, porque el sindicato tendrá legitimación procesal para comparecer en juicio, planteando así una difícil compatibilización con el art. 106 de la ley núm. 12.803. Hazán, Zinara y Charrutti, Ma. Del Luján. "Alcance del los inc. b) y d) del art. $3^{\circ}$ de la ley 17.940”. En el vol. de las XVII Jornadas de Derecho del Trabajo y la Seguridad Social, p. 121. 
no permite equipararla, en caso de colisión, con la libertad sindical positiva receptada en el Convenio Internacional núm. 87 y con la promoción de la actividad sindical del art. 57 de la Constitución (supra cap. III lit. D).

En otro orden, si bien la configuración de la protección a la libertad sindical quedó saldada por la sanción legislativa de la ley 17.940, la norma trajo la inopinada consecuencia de la institucionalización del colectivo sindical, adscripto ahora como titular de derechos procesales y sujeto a eventual consideración de su representatividad en el ámbito del art. $4^{\circ}$ del dec. 165/06.

Por último, queda por verse si en lugar de debatir sobre la conservación o el cambio de modelo de relaciones colectivas de trabajo, no estaremos ante una meseta y una configuración inadvertida y aluvional que termina por cristalizarse en base a un modelo de negociación fuerte e inconfesadamente heterónomo. 